\title{
Maintaining face in the presentation of depression: constraining the therapeutic potential of the consultation
}

\author{
Kristian Pollock \\ University of Nottingham, UK
}

A BSTRACT This article discusses the concerns of patients diagnosed with depression to preserve 'face' in social and medical encounters. The findings are from a qualitative study of patient and GP accounts of the presentation, recognition and treatment of depression. Medical consultations are difficult encounters to accomplish successfully, especially for patients, who often strive to protect their privacy and personal integrity through the maintenance of face. Face work reveals the concern of participants to contribute to the success of the consultation as a social interaction. Patients' strategy of maintaining face helps to account for the commonly reported underdetection of psychosocial distress in general practice consultations. Many people do not regard the experience of psychosocial distress as an appropriate topic for medical consultation or scrutiny. In this case, face work can function as a means of maintaining privacy and resisting medical diagnosis and intervention. The concept of face has relevance in other areas of clinical care, including chronic and enduring pain, functional disorders, medically unexplained symptoms and even terminal illness. Consideration of face work reveals the extent to which the pressure to contribute to the success of the consultation as a social encounter may constrain participants' capacity to realize its therapeutic potential. The extent to which clinical interactions are governed by social etiquette also helps to explain the continuing inertia of the formal health care system and the difficulty of changing the ways that patients and doctors communicate with each other, and of increasing patients' involvement in medical consultations.

KEYWORDS depression; face; medical consultation; qualitative research

A D D RES S Kristian Pollock, Senior Research Fellow, School of Nursing, University of Nottingham, Queen's Medical Centre, Nottingham NG7 2HA, UK. [e-mail kristian.pollock@nottingham.ac.uk] 
ACKNOWLEDGEMENTS I am grateful to the patients and health professionals who took part in the study. The data reported in this article are taken from a larger project supported by the Concordance Research Fellowship, which was funded as part of the Department of Health's Policy Research Programme and administered by the Royal Pharmaceutical Society of Great Britain. I would like to thank Janet Grime, with whom I held the Fellowship jointly, for her helpful comments on an early draft of this article.

Depression is stated to be frequently undetected and poorly treated in general practice (Paykel and Priest, 1992; Tylee, 1995; Hirschfeld et al., 1997; Kessler et al., 1999; Pearson et al., 1999; Anderson et al., 2000; Peveler et al., 2002; Dew et al., 2005). Attention has been directed at the need to improve clinical communication and detection skills (Howe, 1996; Gask et al., 2003). Other reasons for doctors' failure to detect and address depression include pressure of time, deliberate evasion and the feeling that they cannot offer effective treatment or intervention (Chew-Graham et al., 2002; Dew et al., 2005). Patients' reluctance to disclose their experience of emotional distress has been reported in a number of studies (Cape and McCullough, 1999; Cape, 2001; Kadam et al.,2001; Chew-Graham et al.,2002; Gask et al., 2003; Goldstein and Rosselli, 2003; Prior et al., 2003). Reasons for such reticence include feeling constrained by shortage of time, low expectations that the doctor will be able to offer effective help and also the judgement that psychosocial distress is not an appropriate issue to discuss in medical consultations (Cape and McCullough, 1999; Prior et al., 2003; MaGPie Research Group et al., 2005).

Many patients who seek medical help in response to emotional distress and psychosocial difficulties do not anticipate a diagnosis of depression, or want to be treated with antidepressants. Patients' resistance to antidepressants is well established, alongside a preference for counselling and talking therapies rather than drugs (Paykel and Priest, 1992; Priest et al., 1996; Churchill et al., 2000; Chilvers et al., 2001; Grime and Pollock, 2003; Prior et al., 2003). Doubts have been expressed about both the widespread and inappropriate medicalization of distress promoted through the diagnostic label of 'depression' and the necessity or effectiveness of antidepressant treatment for the many cases of mild to moderate depression diagnosed in general practice (Pilgrim and Benthall, 1999; Middleton and Shaw, 2000; Cape, 2001; Prior et al., 2003; Dowrick, 2004; Middleton et al., 2005). This is not to deny the significance and severity of the distress that prompts people to seek help from their doctor, merely to question the necessity or appropriateness of too readily assigning diagnostic labels, or applying medical intervention (most usually the prescription of antidepressants) as an attempted solution. This is recognized in current national and professional prescribing guidelines. Mild to moderate depression is now stated to be a relatively benign and usually self-limiting illness, for which antidepressants are not usually required or even appropriate (Andrews, 2001; NICE, 2004; Middleton et al., 2005; Royal College of Psychiatrists, 2006). 


\section{Pollock: Maintaining Face in the Presentation of Depression}

Investigations of lay understanding of emotional well-being and mental health reveal a widespread expectation that a range of difficulties will have to be confronted throughout life. Rather than seek medical help it is often felt to be desirable and usually possible for the individual to overcome such difficulties by mobilizing the personal and social resources at their disposal (Rogers and Pilgrim, 1997; Pill et al., 2001; Wainwright and Calnan, 2002). From this perspective, patient reticence and medical oversight may constitute adaptive strategies, rather than a cause for concern (Cape and McCullough, 1999). It remains the case, however, that a substantial number of people, including many of the respondents in the present study, consult their doctors about their experience of anxiety and distress when they feel no longer able to cope and, having exhausted the social and personal resources available to them, consider that they have no other obvious place to go for help (Rogers et al., 2001). Awareness of the normative expectations relating to emotional self-reliance combined with expectations about the constitution of medical consultations and the demeanour appropriate to participants may inhibit patients' capacity to communicate the nature or extent of their despair.

People often talk about putting on a 'front' or 'face' as a strategy for concealing their true feelings and responses in social settings and communication with others. This may be done for a number of reasons: as a means of self-concealment and maintaining privacy, to present oneself in a desirable light or as a form of courtesy to protect the feelings and public personae of others. Goffman has defined face as 'an image of self delineated in terms of approved social attributes' (1972a: 5). As an expression of self, face is a 'sacred thing', a 'ritually delicate object', the manifestation of our identity. To lose face is to experience shame and diminished personal and social esteem.

Face is not a fixed personal characteristic or attribute, but the product of interaction with others: a 'joint ceremonial labour' (Goffman, 1972b: 85). In social encounters, people work hard to preserve the face of fellow participants, as well as themselves, since embarrassment to either party causes loss of face to both. Normally, participants can rely on others to collaborate in the protection of their personal face, provided they, in turn, are prepared to reciprocate. Face work involves the carrying out of continuous conversational adjustments and repairs as people work to sustain a mutually acceptable version of affairs and events which deviates to an extent from what each individual really thinks or feels. Typically, preserving face amounts to observing courtesy and being polite. It is a fundamental strategy for successful social interaction. There is a tension between self-respect and consideration of others. Individuals may experience difficulties in sustaining a public persona that is widely divergent from the thoughts and feelings of their 'inner' self. In the event of discrepancies between participants becoming too gross to sustain face, interaction breaks down. In modern industrial democracies, such as North America and the UK, commitment to the norm 
of egalitarianism is very strong. Even encounters between people of highly discrepant social power and status are usually framed in terms of equality and balanced reciprocity (Brown and Levinson, 1978). Violation of face is a significant issue. Failure to receive acknowledgement or achieve credibility is deeply threatening to the individual's sense of self-esteem and personal integrity (Werner and Malterud, 2003).

Relations of intimacy constitute one area where face may be relaxed: we can allow those close to us to see us more nearly as we are. Conversely, formal politeness usually increases in proportion to the difficulty and tension of the social situation. Medical consultations are potentially difficult encounters, especially for patients, because of the inherent role inequality between participants and because the experience of illness and the presentation of personal problems for professional scrutiny are intrinsically face-threatening events (Rogers and Pilgrim, 1997; Jolanki, 2004). Although this applies also to professionals, patients are much more severely disadvantaged in their lack of access to the interactional resources required to maintain face through the construction of a credible moral identity (Taylor and White, 2000).

Issues around the appropriateness of consulting, the legitimation of illness and the nature of lifestyle all raise questions about patient competence and accountability (Robins and Wolf, 1988). Disclosure of emotional distress is particularly problematic. It breaches the privacy of a subjective experience that is highly valued and usually tightly contained. Issuing commands or making any form of demand on other people are both highly facethreatening events (Brown and Levinson, 1978). The exposure of emotional need is particularly challenging outside relations of established intimacy. The medical consultation is consequently a difficult and complex social encounter for all participants to accomplish successfully, especially where they involve psychosocial problems. In these circumstances, concealment and evasion become reasonable strategies of self-protection for professionals as well as patients. Patients may choose to avoid disclosure of their distress rather than risk destroying their composure (Byrne et al., 2002). This strategy may be supported by their doctors:

The fear of not being able to control themselves, of 'losing face', in their [patients'] presentation, leads to the use of techniques which hint or infer the nature of a problem without making any direct statement to this effect.... Both doctor and patient co-operate in this process of containment almost as though they have an obligation to each other to do so. (Stimson and Webb, 1975: 64)

This article discusses patient accounts of maintaining face and the effort to conceal depression. It goes on to discuss the wider consequences of face as a constraint on interactions between patients and health care professionals in a range of clinical settings. 


\section{Method}

The data presented are from two series of patient interviews included within a larger qualitative study of patient and professional perspectives on the recognition and treatment of depression (Pollock and Grime, 2002a; Pollock and Grime, 2003). A convenience sample of 32 patients with recently diagnosed mild to moderate depression was recruited from eight general practices in the West Midlands of England. Practices were selected to include a range of different types and characteristics (e.g. urban, rural, large partnerships and single-handed surgeries). All but two of the patients took part in a followup interview six months after the first (one had died, and another moved out of the area). In order to incorporate the views of patients across a wide spectrum of experience of depression, a further group of 30 respondents was recruited from the regional membership of the Depression Alliance (DA), a leading voluntary organization providing support and information to people affected by depression. These respondents were interviewed once. Most of the Depression Alliance respondents had a longer experience of depression (more than two years) than the patient respondents. The two groups were comparable in terms of age, sex, marital status and occupation. Women outnumbered men by nearly three to one (46 to 16 ). All but three of the interviews were taped and fully transcribed for thematic analysis using NUD*IST to facilitate organization of the material. Untaped interviews and research field notes were typed up from detailed notes and entered into the database. Interviews were loosely structured round a guiding topic list that enabled respondents to introduce and develop issues of particular personal significance. The interview guide covered a range of core issues relating to respondents' ideas about the nature, cause and recognition of depression, the process of seeking help, consultations with GPs and treatment decisions and evaluation. 'Face' was one of the themes that emerged from analysis of the data, rather than one of the issues featuring on the initial list of topics. The study was approved by the local Research Ethics Committee. All identities attributed in the quoted extracts are pseudonyms. Further details of the research methodology are given in the full project report (Pollock and Grime, 2002b).

\section{The salience of 'face'}

Explicit reference to the notion of 'face' was common throughout the interviews, with reference to social, as well as medical, settings. Respondents often attempted to conceal the fact that they suffered from depression from those around them or were very selective about who they told. Most people who adopted such a strategy felt that they were quite successful in hiding their illness even, in some cases, from spouses, family friends and workmates over an extended period of time:

I remember, yes, I was putting on a front. I seemed quite, well, just ordinary in talking, you know. But, oh, underneath, it was just dreadful, really. You know, if 
you pull the curtains back, part of me was just screaming, 'CAN'T YOU SEE, I'M JUST FEELING SO DREADFUL?'. But ... I think I put on a really ... good front. (Susan, DA respondent)

Reluctance about others knowing they suffered from depression was explained in several ways. Some found the diagnosis embarrassing or diminishing. In becoming depressed they felt they had let themselves down by exposing weakness and an inability to cope. Not wanting to worry people, or cause those around them to feel in some way 'guilty' or responsible for the illness and a fear of alienating people and damaging their relationships by imposing too much and 'boring' them with their problems were additional reasons for concealment. The anticipation - or experience - of being misunderstood was a strong disincentive against disclosure:

I wouldn't want to talk about it to anyone I felt wouldn't understand, you know?

Not because of a stigma, but because ... how can I explain? ... it ... it's the feeling that it's just that they don't understand. (Jane, DA respondent)

Many respondents appreciated being able to share their experiences with at least one fellow sufferer. Awareness and identification of other people's distress often followed the recognition and treatment of depression in themselves. Respondents sometimes expressed surprise on discovering that people around them had hidden their depression, and to find that this was, in fact, a very common illness:

Again, you don't know who is covering up, or whatever, and all the people that I sort of know are ... seem to be normal, but then you don't know whether they are or not, do you? I mean, I was quite surprised last year, I went to a party, and this girl, she is very confident and, you know, always the life and soul of the party, and we sat down talking and it came out that she was actually on antidepressants ... and that was - you wouldn't have put her down ... again, she hid it and that helped, actually sort of chatting to her, it did help ... but I didn't tell her that I was because she has got such a big mouth (laughing). (Sonia, Patient respondent)

There was a tension between protecting privacy and the desire to come clean, between concealing and revealing the true self:

$Q$ : So, do you think in fact if you didn't tell them people would ever guess?

$A$ : No, they wouldn't know.

$Q$ : Would you prefer them to know?

$A$ : I don't mind. Yes, in a way, because then it is the true me, isn't it? But if their heads just turn away and they walk off, then I don't want to tell them, because I'd rather have people than not to have people, you know ... (Julia, DA respondent)

Disclosing depression involved a gamble that people were often reluctant to take, fearful that they would lose face and alienate people, even those with whom they had close and valued relationships. However, where disclosure did pay off, respondents described their relief at being free of the burden of concealment: 


\section{Pollock: Maintaining Face in the Presentation of Depression}

I've not really alienated any of my friends long term, but what I found was that when the counselling was really starting to pay dividends in terms of me opening up and being able to talk to people, I did actually start discussing things with my colleagues at work ... and that made it easy for me, because I really didn't have to hide any more ... and there was actually a great sense of relief. (Simon, Patient respondent)

Sustained failure to align the inner self and public persona threatens to render the maintenance of face untenable. For some respondents, the boundary between themselves and their mask had become so blurred that they began to have trouble separating these out:

I wonder, how many other people, speaking to me ... would think, 'Well, in no way is she depressed.' So I find myself thinking, 'Well, then, am I putting it all on?' If that's what everybody would think. I mean, I don't know.... and I wonder, if that's what comes through about me, to anyone that talks, and not everybody could be wrong, and therefore I must be wrong, and therefore I'm not depressed (laughing). If you see what I mean? ... Yes, the facade is so strong, it's almost me, now. (Sarah, DA respondent)

In maintaining face over a prolonged period of time, these respondents had come to doubt both the reality of depression and the authenticity of their own experience where this diverged so greatly from the presumed perceptions of others, which they worked so hard to shape.

\section{Maintaining face in medical consultations}

The fear of being misunderstood and not knowing how to articulate their distress also underlay the difficulties patients experienced in disclosing how they felt in consultations with their doctors:

I think most people look at me and think, 'Oh, well, she's a bit confident. She knows what she's doing ... I put a face on as much as I can ... I do it automatically, now. Which is why my doctor came up with, 'I think you're fine.' (Mary, DA respondent)

The reserve that had become habitual in social settings was frequently perpetuated in medical consultations. There was often a tension and ambivalence between the discipline of observing the norms of composure and self-control and the desire to express distress and disclose the active desire for help. Thus, it could be not so much the need to conceal as being unable to reveal depression that was the problem. People sometimes wanted their defences to be breached, for their problems to be out in the open, but lacked the confidence or ability to disclose them. Where words failed, distress could more effectively be 'shown' by respondents breaking down in tears during the consultation, although this was not reported to be a common occurrence:

I held myself together in the waiting room, but as soon as I got into the doctor's surgery and he said, you know, the usual, 'What can I do for you?', I said, I can't 
actually remember, but I think I struggled together about two or three words and just burst into tears, and just couldn't control it, and that was it. (Peter, Patient respondent)

Several people described being taken unawares by this involuntary reaction. Nevertheless, they appreciated the opportunity to vent their pentup feelings and the usually supportive responses of their doctors. Perhaps, for some respondents, the shock of such extreme behaviour forced them to confront the severity of their distress in a way that catalysed their ability to recognize and start to deal with it. Others described being trapped by the face or mask that concealed their depression even from their doctors: wanting to be able to express their distress and to reveal themselves, but feeling unable unless an appropriate circumstance presented itself, but which they had no power to conjure.

In some contexts, maintaining face through the concealment of depression may be a deliberate, positive choice, a way in which people protect their privacy and subjectivity. In particular, this might be an appropriate response where people feel either that it is not appropriate to bring social and personal problems for medical attention, or that because they anticipate that their doctor is unable to offer them constructive or acceptable treatment, there is no point in doing so (Rogers and Pilgrim, 1997; Pill et al., 2001). However, most of the respondents in this study had consulted their GP because they were actively seeking help to cope with the distress they found so difficult to convey. Some described their sense of being trapped in a kind of double bind, recognizing that their inability to express their distress prevented access to constructive help:

Because a doctor cannot help you if you are not prepared to be honest and open with him. You cannot bake a cake with half a recipe, and I don't feel that a doctor can treat you to the best of his ability if you're withholding - but I learnt that the hard way (laughing). (Sandra, Patient respondent)

The medical consultation presented particular barriers to establishing a relationship with professionals that went beyond face. The formulaic interaction routines often employed by doctors presented additional difficulty for some respondents. Unable to respond appropriately or to create an opportunity to speak freely, they did not talk at all:

Because, I could not say the, you know, normally stock answer - everybody says, 'Fine', you know. I had to tell the truth. I did not know what to say ... If I didn't know the expected answer, I am too frightened to give it in case I get the wrong reaction ... so, if I don't have the formula for the right answer then I have not got an answer. (Karen, DA respondent)

Criticism of professional responses and the failure, or unwillingness, to get behind the face was sometimes more overt:

I think that deep down I probably wanted somebody to ask me the right questions, desperately. I can remember once going to a GP, a long, long time ago, and him 


\section{Pollock: Maintaining Face in the Presentation of Depression}

saying 'How are you?', and I would say, 'I am OK', and I was thinking, 'Why did he ask me "How are you?" What a silly question!' ... And I said, 'I am OK', and, erm ... I think I felt like saying to him, 'Don't ask me, "How are you?", ask me deeper questions', but ... I think as a patient, you can't just sit there and say to a doctor, "Actually, it is silly to say to people, "How are you?" because they will say "I am alright, thank you." Why couldn't he ask me more of a questioning question? Why couldn't he really dig ... sort of, really draw it out ...? (Melanie, Patient respondent)

Along with frustration about professional failure to get behind the face, some respondents expressed awareness of their collusion with doctors to avoid the acknowledgement of distress which would force a confrontation of the problems it expressed (Howe, 1996). For example, the respondent in the preceding extract had a very good relationship with her present GP, and was prepared to tolerate the two-week wait that was often required to get an appointment with her. Nevertheless, even during such hard-won consultations, she sometimes deliberately held back questions and concerns. To utter them would force the doctor to initiate an extended discussion and lengthen a consultation that was already running way behind schedule:

The GP is excellent ... If she has got the time she will give you the time, but sometimes you sense that she is already running half an hour or an hour late, and sometimes I have got there and you daren't, you feel that you dare not say too much, because ... if she is worth her salt, she is going to say, ask you the question, the right question, that is going to start you opening up ... (Melanie, Patient respondent)

Patient consideration and restraint in helping doctors manage the pressures of the consultation, especially shortage of time, was frequently expressed among respondents and is a common finding in this and many other studies (Stimson and Webb, 1975; Tuckett et al., 1985; Cromarty, 1996; Cornford, 1998; Cape and McCullough, 1999; Kadam et al., 2001; Pollock and Grime, 2002a; Gask et al., 2003). It illustrates the work that patients routinely carry out to protect professional face and contribute to the successful conduct of the consultation as a social encounter.

Respondents' perception of appropriateness in relation to the patient role sometimes extended to a sense of obligation to recover:

The first few months it wasn't a problem, but I think he [GP] was looking for me to say I was getting better, and I was thinking, 'I'm not. I can't go back to work.' ... So I remember at the time thinking, 'I'll tell him I've noticed a slight improvement, but I'm just not quite ...' You know what I mean, almost leading him to hear what he wanted to hear so that he would give me what I wanted ... (Carol, Patient respondent)

As this example illustrates, patients attempt to pursue their own agenda in the consultation, although obliged to operate within the constraints of etiquette appropriate to their role. However, failure to improve, if not recover, was felt to be inappropriate and even impolite. The reflexive device of 
'making excuses' for professionals and empathizing with their difficulties including the intractable problems patients recognized themselves to pose for them - was very common. However, where respondents perceived a professional violation of face they were less forgiving. Such incidents provoked overt criticism:

No, the consultant, the psychiatrist in the second hospital that I was in, because I would not talk to him. I was too scared to talk to him. I could tell him that I was too scared to talk to him, and ... he did not get that much information about me. And, em, he said to me, the last time I ever saw him, he said to me, 'In hindsight, looking back, do you think that you might be making mountains out of molehills about your problems?' (laughing). Erm, and I could see why he thought that, because I would not talk to him. But you'd think that somebody with that amount of training could see that some people, they are just too frightened. (Karen, DA respondent)

It is notable that even in this extract, which describes what this respondent perceived to be a highly offensive professional dismissal of her severe and enduring distress, a disclaiming device still comes into play prior to the expression of some fairly sharp criticism. Notwithstanding the acknowledgement that the patient's response is impeding her recovery, it is just this kind of problem that professional expertise is supposed (and paid) to deal with.

\section{Discussion}

In carrying out the face work that contributes to the success of the medical consultation as a social encounter, patients jeopardize their chances of receiving acknowledgement and attention for their distress. The interactive dominance of doctors secures the privileging of professional agendas over those of patients. Patients collude in this process in working to save professional face as well as their own (Kettunen et al., 2001; Edwards et al., 2004; $\mathrm{Li}, 2004)$. The patient contribution to maintaining interaction in the consultation has gone largely unrecognized.

This article has presented data relating to the presentation of face among general practice patients consulting in response to an experience of psychosocial distress, which is conventionally labelled as 'depression'. However, the concept and therapeutically adverse consequences of face work have a much wider application. Li described the collaborative management of relations between nurses and terminally ill cancer patients as involving the maintenance of 'symbiotic niceness'. 'Giving psychosocial care involves the emotional labour of being nice to each other' ( $\mathrm{Li}, 2004: 2573$ ). 'Nice' patients were easy to manage, and rewarded with a positive response. At the other extreme were 'undeserving' or troublesome cases, who were awarded 'obligatory' care, but without niceness. Similar mechanisms can be observed in the underreporting of pain where patients try to maintain a stoical and uncomplaining demeanour or 'front' to the detriment of their physical and emotional well-being (Salmon and Manyande, 1996). More 
generally, it is manifest in the habitual encouragement of positive thought and 'attitude of mind' among sufferers from many forms of chronic and even terminal disease (Pollock, 1993; Byrne et al., 2002; Salmon and Hall, 2003; Werner et al., 2004). Almost all (28/30) of Byrne et al.'s (2002) respondents felt that it was important to suppress the expression of pain and emotional distress in response to cancer. This was partly to protect others from their unhappiness, but also because they feared the catastrophic consequences of such revelation in alienating those around them. Respondents in Byrne et al.'s study felt that they were encouraged by professionals to adopt a positive attitude in 'fighting' cancer, and thus to occupy a social role that others had defined for them. Leydon et al. identified a similar response in their analysis of the illness narratives of cancer patients:

The expression of hope often entailed presenting a brave face to others, and this could itself make it difficult to talk about or seek information regarding cancer. Getting on with life and maintaining a positive outlook was perceived as the approach to managing illness that was most respected by hospital staff, friends and family. The pressure to present a hopeful facade also related to a fear of using up any reserve of sympathy and support from friends and relatives. (2000: 911)

There is evidence that patients have good reason to conform, and that their concern to avoid alienating staff is well grounded. The professional attribution of negative stereotypes to patients who are perceived to be uncooperative, difficult or demanding, is well established (Groves, 1978; Gerrard and Riddell, 1988; Fineman, 1991; Bendelow, 1996; Salmon and Manyande, 1996; Allsop and Mulcahy, 1998; Butler and Evans, 1999; DixonWoods and Critchley, 1999; Paterson et al., 2001; Li, 2004; May et al., 2004; Raine et al.,2004). Patients are aware of these negative stereotypes and strive to avoid them by behaving appropriately and occupying the role of 'good' patient competently (Salmon and Manyande, 1996; Leydon et al., 2000; Byrne et al., 2002; Bastian, 2003; Cohen and Britten, 2003; Werner et al., 2004). The 'good' patient is positive, stoical, co-operative and uncomplaining. To carry off this role with poise requires the maintenance of face.

The metaphor of 'fighting' illness is encouraged and widely admired as a positive and adaptive response to illness, but it does not engage disease. It does, however, suppress the expression of unhappiness which those around the patient, both lay and professional, find difficult to deal with (Salmon and Hall,2003,2004). The rhetoric of patient agency and empowerment around the images of maintaining a positive 'attitude of mind' and 'fighting' illness as an appropriate and desirable means of dealing with chronic and even terminal illness may serve the interests of others (both lay and professional) rather than being of benefit to patients (Pollock, 1993). As the preceding account has shown, the maintenance of face may be adopted as a long- or shortterm strategy of self-protection and promotion, though often attended by considerable ambivalence and difficulty. However, in certain contexts, the imposition of face effectively transfers responsibility for the management of illness to patients and allows the contraction of professional accountability. 
Salmon and Hall suggest that this distancing device is particularly associated with intractable but common conditions, such as depression, pain, chronic and terminal illness and so-called 'functional' disorders, which professionals find emotionally and therapeutically hard to deal with (Lupton, 1997; Butler and Evans, 1999; Salmon and Hall, 2003; Werner and Malterud, 2003). It is in part a consequence of the particular challenges thrown up by the contemporary profile of chronic disease and psychosocial malaise and the limitations of the traditional biomedical model in dealing with these (Dowrick, 2004; May et al., 2004). As their roles become more complex, the medical consultation increases the communicative and interactive demands on both patients and professionals (May et al., 2004). The drive towards patient-centred medicine may be both well intentioned and sometimes beneficial. Metaphors such as 'fighting' illness and adopting a positive 'attitude of mind' may have some value in structuring patient responses to illness, and maintaining social engagement (Pollock, 1993). However, increasing lay responsibility for illness has also worked to patients' disadvantage, in intensifying the personal burden of disease and presenting the opportunity for professional disengagement and reduced accountability for care.

The salience of 'face' as a device for containing distress and managing the social presentation of depression emerged in respondents' accounts of their interaction with health professionals and others in a wide range of work and social settings. Some respondents also described medical encounters which somehow managed to transcend the bureaucratic format of the consultation (Strong, 1979), and the great personal significance of being able to reveal themselves to a supportive and empathetic listener. Others spoke of their ongoing search for such an opportunity. The characteristics of such genuinely therapeutic exchanges and the communicative circumstances which enable them call for further research, and in particular the detailed analysis of recorded interactions between health professionals and patients in consultations dealing with a wide range of conditions, as well as depression.

\section{Limitations of the study}

The salience of face as both a deliberate strategy of self-presentation and a barrier to effective communication with health professionals emerged from respondents' accounts of depression, and had not been anticipated in advance. The data form part of a substantial qualitative investigation of lay and professional constructs of depression as a diagnostic category and how it should most appropriately be treated. The study findings gain support from their similarities with those of other studies of patients' experience of depression and taking antidepressants (Lewis, 1995; Karp, 1996; Kadam et al., 2001; Rogers et al., 2001; Wainwright and Calnan, 2002; Garfield et al., 2004; Haslam et al., 2004). Although the study succeeded in including the views of a diverse range of patients, the DA respondents were self- 
selected and the recruitment of the patient respondents was a difficult and protracted process (Pollock and Grime, 2002b). A number of patients were recruited directly by their GPs, and it is natural that they would be more inclined to ask individuals with whom they had a positive relationship and felt would be 'good' respondents and willing to take part in the research. It is likely that other perspectives were missed, particularly those of patients who were more dissatisfied with their experience of health care and alienated from the service. A further limitation of the present study is that it is based on retrospective accounts of patients of their interactions with doctors. These are valuable as a means of enabling respondents to engage in reflective overview, which in the case of the patients, extended over a six-month follow-up period. However, further research based on direct observation and recording of consultations is required for a more detailed and searching analysis of the communication between doctors and patients in consultations and the significance of face work in the presentation or concealment of psychosocial distress.

\section{Conclusion}

Medical consultations are difficult encounters to accomplish successfully, especially for patients, who often strive to protect their privacy and personal integrity through the maintenance of face. Face work contributes to the success of the consultation as a social exchange, but may impede its therapeutic potential. The strategy of maintaining face helps to account for the common failure of GPs to recognize and address patients' experience of psychosocial distress even when the consultation may have been booked specifically with the intention of disclosing this. However, face work is relevant also to much wider areas of clinical care, including the presentation of chronic and enduring pain, functional disorders, medically unexplained symptoms and even terminal illness. Patients work to conform to the socially sanctioned role of the stoic, good and uncomplaining patient in order to retain the social esteem and good will of others, laymen as well as professionals. In taking upon themselves the internalization of face, and in suppressing the expression of emotional distress, patients are responding to pressures to conform to the socially sanctioned roles that underpin the interactive order of the consultation and contribute to the inertia of formal health care. Health policy has centred on the realization of patient-centred medicine for over a decade. However, attention to the demands of the consultation as a social, rather than a purely clinical, encounter helps to explain why the substance of routine interactions between patients and health professionals has changed very little throughout the past 30 years.

\section{References}

Allsop, J. and Mulcahy, L. (1998). Maintaining professional identity: Doctors' responses to complaints. Sociology of Health and Illness, 20(6), 802-24. 
Anderson, I.M., Nutt, D.J. and Deakin, J.F.W. (2000). Evidence-based guidelines for treating depressive disorders with antidepressants: A revision of the 1993 British Association for Psychopharmacology guidelines. Journal of Psychopharmacology, 14(1), 3-20.

Andrews, G. (2001). Placebo response in depression: Bane of research, boon to therapy. British Journal of Psychiatry, 178, 192-4.

Bastian, H. (2003). Just how demanding can we get before we blow it? British Medical Journal, 326(14 June), 1277-8.

Bendelow, G.A. (1996). A 'failure' of modern medicine? Lay perspectives on a pain relief clinic. In S. Williams and M. Calnan (Eds.), Modern medicine: Lay perspectives and experience, pp. 167-85. London: UCL Press.

Brown, P. and Levinson, S. (1978). Universals in language usage: Politeness phenomena. In E.N. Goody (Ed.), Questions and politeness: Strategies in social interaction, pp. 56-289. Cambridge: Cambridge University Press.

Butler, C.C. and Evans, M. (1999). The 'heartsink' patient revisited. British Journal of General Practice, 49(440), 230-3.

Byrne, A., Ellershaw, J., Holcombe, C. and Salmon, P. (2002). Patients' experience of cancer: Evidence of the role of 'fighting' in collusive clinical communication. Patient Education and Counselling, 48(1), 15-21.

Cape, J. (2001). How general practice patients with emotional problems presenting with somatic or psychological symptoms explain their improvement. British Journal of General Practice, 51(470), 724-9.

Cape, J. and McCullough, Y. (1999). Patients' reasons for not presenting emotional problems in general practice consultations. British Journal of General Practice, 49(448), 875-9.

Chew-Graham, C.A., Mullin, S., May, C., Hedley, S. and Cole, H. (2002). Managing depression in primary care: Another example of the inverse care law? Family Practice, 19(6), 632-7.

Chilvers, C., Dewey, M., Fielding, K., Gretton, V., Miller, P., Palmer, B. et al. (2001). Antidepressant drugs and generic counselling for treatment of major depression in primary care: Randomised trial with patient preference arms. British Medical Journal, 322(31 March), 772.

Churchill, R., Khaira, M., Gretton, V., Chilvers, C., Dewey, M., Duggan, C. and Lee, A. (2000). Treating depression in general practice: Factors affecting patients' treatment preferences. British Journal of General Practice, 50(460), 905-6.

Cohen, H. and Britten, N. (2003). Who decides about prostate cancer treatment? A qualitative study. Family Practice, 20(6), 724-9.

Cornford, C.S. (1998). Why patients consult when they cough: A comparison of consulting and non-consulting patients. British Journal of General Practice, 48(436), $1751-4$.

Cromarty, I. (1996). What do patients think about during their consultations? A qualitative study. British Journal of General Practice, 46(410), 525-8.

Dew, K., Dowell, A., McLeod, D., Collings, S. and Bushnell, J. (2005). 'This glorious twilight zone of uncertainty': Mental health consultations in general practice in New Zealand. Social Science and Medicine, 61 (6), 1189-200.

Dixon-Woods, M. and Critchley, S. (1999). Medical and lay views of irritable bowel syndrome. Family Practice, 17(2), 108-13.

Dowrick, C. (2004). Beyond depression: A new approach to understanding and management. Oxford: Oxford University Press. 


\section{Pollock: Maintaining Face in the Presentation of Depression}

Edwards, C., Staniszweska, S. and Crichton, N. (2004). Investigation of the ways in which patients' reports of their satisfaction with healthcare are constructed. Sociology of Health and Illness, 26(2), 159-83.

Fineman, N. (1991). The social construction of non-compliance: A study of health care and social service providers in everyday practice. Sociology of Health and Illness, 13(3), 354-74.

Garfield, S., Francis, S.-A. and Smith, F. (2004). Building concordant relationships with patients starting antidepressant medication. Patient Education and Counselling, 55(2), 241-6.

Gask, L., Rogers, A., Oliver, D., May, C. and Roland, M. (2003). Qualitative study of patients' perceptions of the quality of care for depression in general practice. British Journal of General Practice, 53(489), 278-83.

Gerrard, T.J. and Riddell, J.D. (1988). Difficult patients: Black holes and secrets. British Medical Journal, 297(20 August), 532-3.

Goffman, E. (1972a). On face work: An analysis of ritual elements in social interaction. In Interaction ritual, pp. 5-45. Harmondsworth: Penguin.

Goffman, E. (1972b). The nature of deference and demeanour. In Interaction ritual, pp. 47-95. Harmondsworth: Penguin.

Goldstein, B. and Rosselli, F. (2003). Etiological paradigms of depression: The relationship between perceived causes, empowerment, treatment preferences, and stigma. Journal of Mental Health, 12(6), 551-63.

Grime, J. and Pollock, K. (2003). Patients' ambivalence about taking antidepressants: A qualitative study. Pharmaceutical Journal, 271(11 October), $516-19$.

Groves, J.E. (1978). Taking care of the hateful patient. New England Journal of Medicine, 298(16), 883-7.

Haslam, C., Brown, S., Atkinson, S. and Haslam, R. (2004). Patients' experiences of medication for anxiety and depression: Effects on working life. Family Practice, 21(2), 204-12.

Hirschfeld, R.M., Keller, M.B., Panico, S., Arons, B.S., Barlow, D., Davidoff, F. et al. (1997). The national depressive and manic-depressive association consensus statement on the undertreatment of depression. Journal of the American Medical Association, 277(4), 333-40.

Howe, A. (1996). 'I know what to do, but it's not possible to do it': General practitioners' perceptions of their ability to detect psychological distress. Family Practice, 13(2), 127-32.

Jolanki, O. (2004). Moral argumentation in talk about health and old age. health:; 8(4), 483-503.

Kadam, U.T., Croft, P., McLeod, J. and Hutchinson, M. (2001). A qualitative study of patients' views on anxiety and depression. British Journal of General Practice, 51(466), 375-80.

Karp, D. (1996). Speaking of sadness: Depression, disconnection and the meanings of illness. New York: Oxford University Press.

Kessler, D., Lloyd, K., Lewis, G. and Pereira Gray, D. (1999). Cross sectional study of symptom attribution and recognition of depression an anxiety in primary care. British Medical Journal, 318(13 February), 436-40.

Kettunen, T., Poskiparta, M., Liimatainen, L., Sjogren, A. and Karhila, P. (2001). Taciturn patients in health counselling at a hospital: Passive recipients or active participators? Qualitative Health Research, 11(3), 399-410. 
Lewis, S.E. (1995). A search for meaning: Making sense of depression. Journal of Mental Health, 4(4), 369-83.

Leydon, G.M., Boulton, M., Moyhihan, C., Jones, A., Mossman, J., Boudioni, M. and McPherson, K. (2000). Cancer patients' information needs and information seeking behaviour: In depth interview study. British Medical Journal, 320(1 April), 909-13.

Li, S. (2004). 'Symbiotic niceness': Constructing a therapeutic relationship in psychosocial palliative care. Social Science and Medicine, 58(12), 2571-83.

Lupton, D. (1997). Doctors on the medical profession. Sociology of Health and Illness, 19(4), 480-97.

MaGPie Research Group, Bushnell, J., McLeod, D., Dowell, A., Salmond, C., Ramage, S. et al. (2005). Do patients want to disclose psychological problems to GPs? Family Practice, 22(6), 631-7.

May, C., Gayle, A., Chapple, A., Chew-Graham, C.A., Dixon, C., Gask, L. et al. (2004). Framing the doctor-patient relationship in chronic illness: A comparative study of general practitioners' accounts. Sociology of Health and Illness, 26(2), 135-58.

Middleton, H. and Shaw, I. (2000). Distinguishing mental illness in primary care. British Medical Journal, 320(27 May), 1420-1.

Middleton, H., Shaw, I., Hull, S. and Feder, G. (2005). NICE guidelines for the management of depression. British Medical Journal, 330(5 February), 267-8.

NICE. (2004). Depression: Management of depression in primary and secondary care. London: NICE.

Paterson, B.L., Russell, C. and Thorne, S. (2001). Critical analysis of everyday selfcare decision making in chronic illness. Journal of Advanced Nursing, 35(3), $335-41$.

Paykel, E.S. and Priest, R.G. (1992). Recognition and management of depression in general practice: Consensus statement. British Medical Journal, 305 (14 November), 1198-202.

Pearson, S.D., Katzelnick, D.J., Simon, G.E., Manning, W.G., Helstrad, C.P. and Henk, H.J. (1999). Depression among high utilizers of medical care. Journal of General Internal Medicine, 14, 461-8.

Peveler, R., Carson, A. and Rodin, G. (2002). Depression in medical patients. British Medical Journal, 325(20 July), 149-52.

Pilgrim, D. and Benthall, R.P. (1999). The medicalisation of misery: A critical realist analysis of the concept of depression. Journal of Mental Health, 8(3), 261-74.

Pill, R., Prior, L. and Wood, F. (2001). Lay attitudes to professional consultations for common mental disorder. British Medical Bulletin, 57, 207-19.

Pollock, K. (1993). Attitude of mind as a means of resisting illness. In A. Radley (Ed.), Worlds of illness: Biographical and cultural perspectives on health and disease, pp. 49-70. London: Routledge.

Pollock, K. and Grime, J. (2002a). Patients' perceptions of entitlement to time in general practice consultations for depression: Qualitative study. British Medical Journal, 325(28 September), 687.

Pollock, K. and Grime, J. (2002b). Understanding depression and its treatment: GP, patient and pharmacist perspectives. Final report of the Concordance Fellowship. Keele University, Department of Medicines Management.

Pollock, K. and Grime, J. (2003). General practitioners' perspectives on managing time in consultations with patients suffering from depression: A qualitative study. Family Practice, 20(3), 262-9. 


\section{Pollock: Maintaining Face in the Presentation of Depression}

Priest, R.G., Vize, C., Roberts, A., Roberts, M. and Tylee, A. (1996). Lay people's attitudes to treatment of depression: Results of opinion poll for Defeat Depression Campaign just before its launch. British Medical Journal, 313 (5 October), 858-9.

Prior, L., Wood, F., Lewis, G. and Pill, R. (2003). Stigma revisited: Disclosure of emotional problems in primary care consultations in Wales. Social Science and Medicine, 56(10), 2191-200.

Raine, R., Carter, S., Sensky, T. and Black, N. (2004). General practitioners' perceptions of chronic fatigue syndrome and beliefs about its management, compared with irritable bowel syndrome: Qualitative study. British Medical Journal, 328(28 May), 1354-7.

Robins, L.S. and Wolf, F.M. (1988). Confrontation and politeness strategies in physician-patient interactions. Social Science and Medicine, 27(3), 217-21.

Rogers, A. and Pilgrim, D. (1997). The contribution of lay knowledge to the understanding and promotion of mental health. Journal of Mental Health, 6(1), 23-36.

Rogers, A., May, C. and Oliver, D. (2001). Experiencing depression, experiencing the depressed: The separate worlds of patient and doctors. Journal of Mental Health, 10(3), 317-33.

Royal College of Psychiatrists. (2006). Depression. London: Royal College of Psychiatrists (pamphlet).

Salmon, P. and Hall, G.M. (2003). Patient empowerment and control: A psychological discourse in the service of medicine. Social Science and Medicine, 57(10), 1969-80.

Salmon, P. and Hall, G.M. (2004). Patient empowerment of the emperor's new clothes. Journal of the Royal Society for Medicine, 97(2), 53-6.

Salmon, P. and Manyande, A. (1996). Good patients cope with their pain: Postoperative analgesia and nurses' perceptions of their patients' pain. Pain, 68(1), $63-8$.

Stimson, G. and Webb, B. (1975). Going to see the doctor: The consultation process in general practice. London: Routledge \& Kegan Paul.

Strong, P. (1979). The ceremonial order of the clinic: Patients, doctors and medical bureaucracies. London: Routledge \& Kegan Paul.

Taylor, C. and White, S. (2000). Practising reflexivity in health and welfare: Making knowledge. Buckingham: Open University Press.

Tuckett, D., Boulton, M., Olson, C. and Williams, A. (1985). Meetings between experts: An approach to sharing ideas in medical consultations. London: Tavistock.

Tylee, A. (1995). How to improve depression detection rates. Primary Care Psychiatry, 1(Supp.), 9-13.

Wainwright, D. and Calnan, M. (2002). Work stress: The making of a modern epidemic. Buckingham: Open University Press.

Werner, A. and Malterud, K. (2003). It is hard work behaving as a credible patient: Encounters between women with chronic pain and their doctors. Social Science and Medicine, 57(8), 1409-19.

Werner, A., Widding Isaksen, L. and Malterud, K. (2004). 'I am not the kind of woman who complains of everything': Illness stories on self and shame in women with chronic pain. Social Science and Medicine, 59(5), 1035-45. 
health: 11(2)

\section{Author biography}

KRISTIAN POLLOCK is a senior research fellow in the School of Nursing at Nottingham University, UK. Her research interests include lay and professional constructions of health and illness, with particular reference to mental health, information as a resource in responding to illness and issues around concordance in medical consultations. Her book Concordance in medical consultations: A critical review was published by Radcliffe Publishing in 2005. 